\title{
A Perspective on Livestock-Wolf Interactions on Western Rangelands
}

\author{
By Stewart Breck, Patrick Clark, Larry Howery, Douglas Johnson, Bryan Kluever, \\ Samuel Smallidge, and Andres Cibils
}

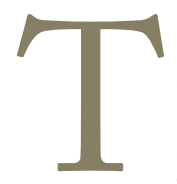

he reintroduction of wolves into their historical ranges in the North American Rocky Mountains and areas of the southwestern United States is possibly one of the most ambitious ecosystemrestoration efforts of the recent past. This initiative has been controversial and has stimulated considerable debate among concerned stakeholders about the feasibility of harmonizing multiple land-use demands when preservation of a large predator becomes a central management goal. In many areas, ranching has taken center stage of this debate as ranchers and land managers seek to develop sustainable ways to manage livestock on landscapes with wolves.

The challenges associated with wolf restoration programs vary regionally and depend on a myriad of interacting factors. Wolf population size and consequent regulatory and legal frameworks; site-specific, biophysical features; and local traditions, perceptions, and attitudes of urban vs. ranching communities are only a few of the issues driving the diversity of situations. Because of this complexity, "silver-bullet" approaches are unlikely to provide answers that will satisfy all stakeholders in all locations. In this context, our article seeks to 1) provide a science-based perspective to inform the wolf-livestock ongoing debate; and 2) suggest research approaches that could lead to locally relevant solutions. Of paramount importance is better understanding of direct and indirect effects of wolves on livestock, and development of effective methods for minimizing impacts while maintaining ecologically relevant wolf populations on the landscape. We argue that progress (i.e., optimizing coexistence or minimizing conflict) is most likely if multiple tools and techniques are used in a context-dependent fashion and integrated into a science based operation supported by producers.

\section{Indirect Effects of Predators on Livestock Foraging Behavior in the Southwest}

Top predators can trigger behavioral responses by prey species (e.g., encounter avoidance, escape facilitation, and increased vigilance) that can have important consequences for ungulate behavioral ecology. ${ }^{1,2}$ Sacrificing foraging efficiency by increasing vigilance because of a perceived threat is a tactic commonly used by prey species foraging in the presence of predators. ${ }^{3-5}$ Actual predation events, as well as social and environmental factors, can influence vigilance rates of prey species that forage in the presence of predators. Moreover, prey response to a particular predator species may vary depending on the environmental and evolutionary history of predatorprey relationships, as well as on the unique hunting strategy of the predator species. ${ }^{6}$ Furthering our understanding of the indirect effects predators may have on foraging behavior of domestic animals can elucidate livestock management practices in areas where predators and prey coexist. Below, we describe field and controlled studies that we conducted to examine the indirect (nonlethal) effects of predators or predator stimuli on cattle foraging behavior. ${ }^{7,8}$

We conducted a field study during which we observed adult cows in an area of eastern Arizona where wolves and mountain lions were common threats to cattle. ${ }^{1}$ This study was designed to 1) compare vigilance rates of cattle to those reported for wild ungulates, 2) determine whether actual predation events on calves influenced vigilance rates of mother cows, and 3) determine whether social and environmental factors influence vigilance rates of cattle.

Scan samples $(n=8,520)$ were collected on 213 cows from May to August 2005 and 2006 during morning and afternoon peak foraging hours. Cattle responded to social and environmental factors in ways similar to wild ungulates. For example, mother cows significantly increased vigilance rates when they 1) foraged with calves at heal, 2) lost a calf to predation, 3) foraged in smaller groups, and 4) foraged in habitats with higher visual obstruction from plants. Overall, vigilance rates for cattle were comparatively lower than were those measured for wild ungulates, apparently, because observations were made only during peak foraging hours and/ or the process of domestication has engendered decreased vigilance in cattle.

We also conducted a controlled pen study at the University of Arizona West Campus Agriculture Center in Tucson, Arizona. ${ }^{8}$ The objective of this study was to examine how the presence of predator or nonpredator stimuli (olfactory and visual) affected 1) vigilance rates, 2) foraging 
rates, 3) giving-up density of high-quality forage, and 4) use of high-quality forage locations by cattle. Eighteen cows were observed during 428,10-minute, experimental trials in a 0.25 -ha dry-lot pasture that contained a choice between high-quality and low-quality foods. All cattle had previous experience with mountain lions and mule deer, and 8 of the 18 had previous experience with wolves. Wolf, mountain lion, mule deer, or no stimuli were placed alongside the high-quality food during each individual trial. Cattle reacted most negatively to wolf stimuli (i.e., cattle were most vigilant and foraged least when wolf stimuli were present), neutrally to mountain lion stimuli (i.e., cattle responses were similar to controls for all dependent variables), and positively to deer stimuli (i.e., cattle foraged most and spent more time in the high-quality location when deer stimuli were present). We detected no difference in behavior between cattle with and without experience of wolves, but our results were confounded making it difficult to tease out the importance of previous experience. ${ }^{8}$

In the field study, cattle responded similarly to free-ranging wild ungulates when foraging in the presence of predators. A unique finding of our field study was that immediately after an actual predation event on calves, individual mother cows dramatically increased their vigilance rates, but those rates returned to baseline 10-12 days after the predation event. In the controlled study, cattle responded negatively to wolf, neutrally to mountain lion, and positively to deer stimuli.

\section{Wolf-Livestock Interactions in the Northern Rocky Mountains}

In 1995 and 1996, gray wolves (Canis lupus) were reintroduced to Yellowstone National Park and central Idaho by the US Fish and Wildlife Service. This large carnivore had been absent since the 1930s, and, as an apex predator, has induced changes in both the natural ecosystems and livestock-production systems of the northern Rocky Mountains. Wolf numbers and range have increased steadily since their reintroduction. By 2010, there were at least 705 wolves in Idaho, 566 in Montana, and 343 in Wyoming. Wolf packs were first confirmed in Oregon and Washington State in 2008, and these state populations increased to 21 and 16 individuals, respectively, by 2010. As wolves have expanded their range, reports of livestock depredation have also increased in the Northern Rocky Mountain region. The extent and magnitude of wolf reintroduction effects on regional livestock production, however, remain largely unknown. In fact, considerable controversy exists regarding the effect of wolves on livestock-rearing systems. ${ }^{9,10}$ One contention is that livestock harried by wolves become stressed, forage less efficiently, gain fewer pounds, and may have more difficulty rebreeding and producing offspring. It has also been suggested wolf presence may alter distribution or habitat-selection patterns of livestock and wild ungulates. Numerous studies have examined wolf-wild-prey species interactions and feedback mechanisms. Recent studies in
Yellowstone National Park (YNP)i found reintroduction of wolves changed elk habitat-selection patterns ${ }^{11}$ and, in some cases, seemed to elicit recovery responses in riparian vegetation, ${ }^{12}$ where, presumably, shifts in habitat selection away from woody riparian areas reduced elk browsing pressure on juvenile cottonwood. In contrast, research in the Greater Yellowstone Ecosystem found willow consumption by wintering elk increased as risk of wolf predation increased. ${ }^{13}$ Consequently, our understanding of the ecological effects of wolf reintroduction, even within YNP, where livestock are absent, is quite incomplete. ${ }^{14}$

A more complicated situation exists on rangelands occupied by livestock, wild ungulates, and wolves. Some recent work has been done in the northern Rocky Mountains, $5,16,17$ but most of our limited understanding of wolf-livestock interactions is based primarily on older studies from Canada, Europe, and the upper Midwest. No study, however, has rigorously evaluated the environmental consequences of these interactions. If cattle and elk respond similarly to wolf presence by reducing riparian occupation, total impacts on riparian vegetation and stream water quality may be reduced. Will this shift in ungulate distribution then result in concentrated use and effects on preferred sites in the uplands? Will this shift also increase interspecific competition between sympatric ungulates, thus, reducing their productivity and, in the case of cattle, profitability? The true magnitude and extent of wolf reintroduction effects on grazed rangelands is essentially unknown.

The objective of our research was to evaluate effects of wolf presence on cattle habitat selection, terrain use, activity budgets, expression of predation-avoidance behavior, and productivity. Studies were initiated on two US Forest Service (USFS) grazing allotments in central Idaho during 2005 and on eight USFS allotments in western Idaho/eastern Oregon during 2008. A paired-longitudinal design was used in central Idaho and a before-after/control-impact (BACI) design with four spatial replications was used in the Oregon/Idaho study. We were particularly interested in wolf-presence effects on cattle preference for critical, but vulnerable, resources, such as riparian areas. We questioned whether wolf presence might increase or decrease the frequency and/or duration cattle occupation of riparian areas.

The complexity of interacting factors affecting livestock behavior, productivity, and predator-prey relationships in the northern Rocky Mountains, however, precludes any conclusive reporting from the studies we have conducted so far. Only through longer-term (10+ years) research, carefully rep-

\footnotetext{
' For an in-depth discussion of results of 16 years of research addressing the effects of wolf reintroduction in Central Yellowstone, please see chapters 16-25 in GARROTt, R. A., P. J. WHITE, AND F. G. R. WATSON. 2009. The ecology of large mammals in central Yellowstone: sixteen years of integrated field studies. Volume 8. San Diego, CA, USA: Academic Press. 693 p. Available at: http://www.sciencedirect.com/ science/book/9780123741745.
} 
licated in both time and space (e.g., BACI design), will it be possible to report conclusive results in this type of ecosystem. ${ }^{9}$ The reader is seriously cautioned, therefore, to interpret the following as only preliminary results that may very likely change as additional data are collected during the course of these long-term studies.

At our study sites in central Idaho, collared, mature beef cows with calves alongside exhibited considerable variability in their preference for riparian or near-stream habitats. Some individuals exhibited a neutral to slightly positive preference (use/availability = 1 to 1.5 ) for areas within $10 \mathrm{~m}$ and areas between $10 \mathrm{~m}$ and $100 \mathrm{~m}$ from perennial streams. On the other extreme, some cows exhibited a very strong preference (use/availability $>3$ ) for the $0-10 \mathrm{~m}$ and $10-100$ $\mathrm{m}$ stream buffers.

Study-site averages for near-stream preference-index values generally ranged from 2 to 2.7 indicating fairly strong, positive selectivity for these habitats by collared cattle, although there was variability in near-stream preference among pastures and among years. Differing terrain and riparian vegetation structure may explain the variability in cattle preference among pastures. Pastures dominated by glacial canyons with very steep canyon walls tend to limit cattle from accessing upland habitats. Pastures with more open, less-confining terrain offered cattle more range-use choices. Brushy, willow-dominated riparian areas presented a visual obstruction for cattle occupying those areas. More open, herb and low-stature, shrub-dominated, riparian areas offer a greater field of view to prey animals attempting to avoid wolf predation. Annual variability in cattle preference for near-stream habitats may be explained by growing conditions and forage productivity, which varied among years. Wolf presence and predation levels on cattle also varied among years. Ongoing evaluations are testing the strength of relationships among varying wolf-presence levels, vegetation, and environmental factors relative to variability observed in cattle preference for near-stream habitats.

Cattle activity budgets in central Idaho were defined as a composite of six possible activity types, classified based on cattle-movement rates or velocities derived from sequential global positioning system (GPS) locations. Activity budgets were remarkably consistent among individual cows but varied among years. Before summer 2008, cattle activity budgets were dominated by stationary $(0-0.01 \mathrm{mph})$ activity (e.g., bedding, ruminating, or standing alert). In 2008, cattle activity appeared to have shifted to much-fewer stationary periods and more time engaged in very slow $(0.01-0.06 \mathrm{mph})$ and slow (0.06-0.25 mph) movement (e.g., foraging). Currently, it is unclear whether this apparent activity shift was due to changes in collar technology, GPS-location-collection rates, or some set of environmental or ecological factors. It is possible that more GPS-location errors accrued when the new, custom-GPS technology was applied in the very rugged terrain of central Idaho, relative to that observed with older, commercial technology. This would decrease the number of locations classified as stationary and inflate the apparent amount of slow and very slow movement. By intensifying the GPS location-collection rate from 30 minutes to 5 minutes, we may have detected brief, slow and very slow movement episodes not detected by the coarser collection interval. A1ternatively, these data may reflect real shifts in cattle activity, possibly due to differing wolf-presence levels.

Wolf presence on the central Idaho study sites was determined for each cattle-occupied area (i.e., pasture plus a 1-km bounding buffer) by comparing data collected through a combination of monitoring techniques, including GPS tracking collars, very high-frequency radiotelemetry collars, scat survey routes, and direct observation. Wolf presence for the periods when cattle were in each pasture was classified into high, moderate, or low levels, based on these monitoring data. Presence levels for each pasture period were averaged to determine a presence level for the entire study site during a grazing season. Wolf presence before the 2008 season was variable but generally tended to be higher than it was during 2008 when wolves appeared to be largely absent.

Concurrent field collections of direct observation data and GPS tracking collar data revealed the GPS technologies were capable of detecting cattle bunching and sustained-flight events, even at a 30-minutes sampling interval, if the collar sample size was adequate for the herd size. In cases where bunching events were directly observed, up to 100 head of cattle were seen remaining tightly massed and vocalizing for up to 1 hour before dispersing. These bunching events tended to occur in upland habitats, where vegetation stature was low and the terrain afforded an extensive field of view. These bunching events, when identified using GPS tracking data, typically appeared at first glance, to be two-three collared cows bedding (i.e., each having many, consecutive, stationary, GPS locations) in close proximity to each other but in an unusual bedding site. Actual bedding sites on open, breezy ridgetops, however, were difficult to separate from bunching-event sites. Sustained-flight or relocation events occur when a prey animal moves a considerable distance from an area of high-predation threat to an area of lower-predation threat. Sustained-flight events were evident in GPS tracking data as linear paths consisting primarily of fast (0.62-1.2 $\mathrm{mph}$ ) and very fast $(>1.2 \mathrm{mph}$ ) movement extending more than 0.5 miles in length. These flight events were particularly evident if they occurred between 10:00 pm and 3:00 am, when cattle should typically be bedded following the evening foraging bout. Various situations or stimuli (e.g., herdsmanship activities, sudden storms, or wind events) could result in GPS collar-location patterns that resemble predator-induced bunching or sustained flight events. Consequently, we will continue to acquire additional, concurrent direct observations and GPS collar data from bunching, sustained-flight, and nonpredator-related events. In due time, we intend to use these data to conduct a rigorous evaluation of the accuracy of event classification when only cattle GPS tracking-collar data are used. 


\section{The Role of Science for Optimizing Wolf- Livestock Coexistence: Goals, Challenges, and Future Research}

The restoration of wolves is an exceptionally contentious issue, but in areas where both wolves and livestock have a legal right to exist, the task of natural resource professionals is to help optimize coexistence and efforts should focus on maintaining viable livestock operations and sustainable wolf populations. Research goals that will be particularly informative include 1) developing effective tools for reducing wolf-livestock conflict, particularly methods that can be implemented in open-grazing situations; 2) understanding the effect of lethal removal (e.g., hunting, control actions) on the sustainability of wolf populations; and 3) understanding the economic effects (both positive and negative) of wolves in rural communities. An important consideration in any research effort is the size of the wolf population because research emphasis will differ for small and recovering wolf populations vs. well-established populations that can tolerate higher per-capita losses without jeopardizing the population. For example, in the northern Rockies where wolves have met and exceed recovery criteria, hunting will play an important role in the population dynamics of wolves, in reducing conflict, and in the overall economic scheme of rural communities. In contrast, small populations like in Arizona and New Mexico will necessarily have a different focus, where illegal take and the effect of control operations will be important considerations, as will the developing and testing of nonlethal tools.

It is paramount that research is framed with realistic expectations. The most important of which is that, even under ideal conditions, where wolves and livestock coexist on the landscape wolves will likely kill livestock, and as a result, some wolves will likely be removed. It is unproductive to expect otherwise, primarily because unrealistic expectations can impede discovery of important information. This is particularly true for developing and testing of nonlethal tools, where often, the unrealistic expectation is to find techniques that permanently stop wolves from killing livestock without resorting to lethal control. Under these conditions, it is common to state the research question as Does this tool work? Under these conditions, all nonlethal tools will eventually fail, which encourages dismissal of the tool as useless. Realizing that all nonlethal tools have limited effectiveness, more-useful questions emerge, such as How long does it work? Under what ecological contexts is it most effective? What are the economic challenges to implementing the tool? Answers to these questions are more likely to help managers optimize coexistence.

An important paradigm emerging from wolf-livestock conflict is that managers with small or recovering populations of wolves tend to stress nonlethal management of wolves, which offers good opportunities for research in this area. Although there will always be a need for further developing and testing of nonlethal methods as wolf populations grow, work on nonlethal tools tends to decrease and the needs shift to understanding wolf-population dynamics and the effects of lethal control. Where there are opportunities to pursue nonlethal research, it is important to not only evaluate the efficacy of the tool but also to evaluate its costs for implementation and acceptance by key stakeholders. Randomization, replication, and control are critical components of any study design, but conducting research in a wolf-livestock system brings additional challenges that make meeting the needs of this core triad more difficult. Challenges that are particularly problematic in wolf-livestock systems include passionate interest groups, ownership of livestock, and lack of trust between producers and researchers. Accommodating these additional challenges can weaken study design and ultimately reduce reliability of study results. Whenever possible, such compromises should be avoided.

For example, a central issue associated with wolves and cattle is a poor understanding of their true effect on livestock, especially in open-range situations. Of primary importance is more thorough understanding of the economic effects that wolves have on livestock producers, including direct ${ }^{13}$ and indirect effects. ${ }^{7,8} \mathrm{~A}$ key to issues is understanding producerdetection rates (i.e., the number of livestock killed by wolves, found by producers, and correctly identified as to cause of death). ${ }^{18}$ Gaining reliable information about wolf-caused mortality and producer-detection rates by studying livestock requires producers to tolerate a research program with onerous needs. Namely, producers must be willing to have their livestock monitored, knowing that information garnered by researchers cannot be used, over the short term, to alter livestock-management practices or predator-management activities. This demand on producers dictated by the study design can be an exceptionally difficult to accept and abide by because of the strong economic ties to their livestock and may be further complicated by negative attitudes toward wolves. Most livestock producers generally have little interest in coexisting with wolves and, therefore, little interest in participating in a research program, unless it has clear and immediate benefits to their operation. When research focuses on livestock, we recommended that a monetary compensation scheme be established that provides incentive and financial gain for tolerating research activities. Producers should also be made aware that using information garnered from a project to manage cattle or wolves prematurely (i.e., before the study has been completed) has the potential to bias the results so that it appears wolves kill less than they might have. Because of the heated nature of wolf-livestock issues, some producers may not be willing to collaborate on studies; in which case, working with other producers can improve the research environment but may come at the cost of jeopardizing important study-design issues, such as randomization. Furthermore, studies of wolf impacts on livestock that are focused on particular groups of livestock may not accurately capture the effect of wolves because depredation events can vary greatly across time and space. A better research approach may be to focus research efforts on wolves and garner knowledge on their prey selection and predation rates. By focusing 
on wolves, rather than cattle, there is likely a greater chance of accurately quantifying the effect of wolves across a broader spatial scale without compromising study design and placing difficult demands on livestock producers.

\section{Preliminary Management Recommendations}

Results from studies conducted in Arizona suggest several management applications to reduce the indirect effects of predation on cattle foraging behavior and to address animal distribution challenges: 1) increased range riding and monitoring of mother cows during the calving season could help reduce both direct and indirect effects of predation, 2) synchronized calving season so it occurs in locations with no or low wolf density could help reduce predation events on calves and temporary declines in foraging by mother cows, 3) increased communication with wildlife biologists about the locations of collared wolves could help livestock managers plan livestock movements in pastures that contain no or low wolf threats, and 4) increased numbers, that is, cattle that forage in larger groups or in the same areas as wild ungulates may forage more efficiently under the "many eyes" hypothesis.

The northern Rocky Mountains is a complex ecological system involving numerous interacting factors; consequently, it will require at least several more years of data collection before firm conclusions can begin to be drawn from these studies. When developing grazing plans, however, cattle producers and natural managers of the northern Rockies should consider that the presence of reintroduced gray wolves may influence cattle distribution and behavior, and these effects may continue for some time after wolves have left or have been removed from the grazing area.

Better understanding wolf impacts on livestock in open grazing systems will be necessary to test methods that reduce wolf predation on cattle. It is likely that the greatest advances in this area will come from more intensive management of livestock (e.g., herding, night penning, and clumping) combined with wolf management strategies (lethal and nonlethal). To determine the efficacy of these strategies as well as their cost effectiveness, good study design combined with management activities will expedite the learning process. Because of the scale of such an effort, it will be necessary to form a team consisting of researchers, livestock producers, and resource managers that trust one another and are committed to pursuing sound science.

\section{Acknowledgments}

This article summarizes a series of papers presented at a symposium entitled "Wolf-livestock interactions: using science to develop innovative management to protect natural and cultural resources" held at the 62nd Annual Meeting of the SRM in Albuquerque, New Mexico, in 2009. The symposium was sponsored by the New Mexico Cooperative Extension Service, the New Mexico State University Range Improvement Task Force, and the Department of Animal and Range Sciences at New Mexico State University.

\section{References}

1. Laundré, J. W., L. Hernandez, and K. B. Altendorf. 2001. Wolves, elk and bison: reestablishing the "landscape of fear" in Yellowstone National Park, USA. Canadian Journal of Zoology 79:1401-1409.

2. Wirsing, A. J., And W. J. Ripple. 2011. A comparison of shark and wolf research reveals similar behavioral responses by prey. Frontiers in Ecology and the Environment 9:335-341.

3. Quenette, P.Y.1990. Functions of vigilance behavior in mammals: a review. Acta Oecologica 11:801-818.

4. Kats, L. B., And L. M. Dill. 1998. The scent of death: chemosensory assessment of predation risk by prey animals. Ecoscience 5:361-394.

5. Swanson, C. C., C. M. Dassube, and J. A. Jenks. 2002. Whitetailed deer behavioral response to predator feces. Proceedings of the South Dakota Academy of Science 81:143-146.

6. Apfelback, R., C. D. Blanchard, R. J. Blanchard, R. S. Hayes, and I. S. McGregor. 2005. The effects of predator odors in mammalian prey species: a review of field and laboratory studies. Neuroscience and Biobehavioral Reviews 29:11231144.

7. Kluever, B. M., S. W. Breck, L. D. Howery, P. R. Krausman, and D. L. Bergman. 2008. Vigilance in cattle: the influence of predation, social interactions and environmental factors. Rangeland Ecology \& Management 61:321-328.

8. Kluever, B. M., L. D. Howery, S. W. Breck, and D. L. Bergman. 2009. Predator and heterospecific stimuli alter behaviour in cattle. Behavioural Processes 81:85-91.

9. Неввlewhite, M. 2011. Unreliable knowledge about economic impacts of large carnivores on Bovine calves. Journal of Wildlife Management 75:1724-1730.

10. Muhly, T. B., And M. Musiani. 2009. Livestock depredation by wolves and the ranching economy in the northwestern U.S. Ecological Economics 68:2439-2450.

11. Mao, J. S., M. S. Boyce, D. W. Smith, F. J. Singer, D. J. Vales, J. M. Vore, And E. H. Merrill. 2005. Habitat selection by elk before and after wolf reintroduction in Yellowstone National Park. Journal of Wildlife Management 69:1691-1707.

12. Ripple, W. J., and R. L. Beschta. 2003. Wolf reintroduction, predation risk, and cottonwood recovery in Yellowstone National Park. Forest Ecology and Management 184:299-313.

13. Creel, S., and D. Christianson. 2009. Wolf presence and increased willow consumption by Yellowstone elk: implications for trophic cascades. Ecology 90:2454-2466.

14. Pyare, S., And J. Berger. 2003. Beyond demography and delisting: ecological recovery for Yellowstone's grizzly bears and wolves. Biological Conservation 113:63-73.

15. Oakleaf, J. K., C. Mack, and D. L. Murray. 2003. Effects of wolves on livestock calf survival and movements in central Idaho. Journal of Wildlife Management 67:299-306.

16. Bradley, E. H., and D. H. Pletscher. 2005. Assessing factors related to wolf depredation of cattle in fenced pastures in Montana and Idaho. Wildlife Society Bulletin 33:1256-1265.

17. Laporte, I., T. B. Muhly, J. A. Pitt, M. Alexander, And M. Musiani. 2010. Effects of wolves on elk and cattle behav- 
iors: implications for livestock production and wolf conservation. PLOS ONE 5:e11954.

18. Breck, S. W., B. M. Kluever, M. Panasci, J. Oakleaf, D. L. Bergman, W. Ballard, and L. Howery. 2011. Factors affecting predation on calves and producer detection rates in the Mexican wolf recovery area. Biological Conservation 144:930-936.

Authors are Research Scientist, USDA-WS National Wildlife Research Center, Ft. Collins, CO 80521, USA (Breck); Range Scientist, USDA-ARS NW Watershed Research Center, Boise, ID 83712, USA (Clark); Professor and Rangeland Extension Specialist, School of Natural Resources and Environment, University of Arizona, Tucson, AZ 85721, USA (Howery); Profes- sor, Department of Rangeland Ecology, Oregon State University, Corvallis, OR 97331, USA (Johnson); Senior Wildlife Biologist, Hayden-Wing Associates, Laramie WY 82072 (Kluever); Assistant Professor and Wildlife Specialist, New Mexico Cooperative Fish and Wildlife Research Unit, College of Agricultural, Consumer and Environmental Sciences, New Mexico State University, Las Cruces, NM 88003, USA (Smallidge); and Associate Professor, Dept of Animal and Range Sciences, New Mexico State University, Las Cruces, NM 88003, USA, acibils@nmsu.edu (Cibils). P. Clark and D. Johnson wish to thank the USDA Agricultural Research Service, Oregon Beef Council, and Oregon State University for funding and support of this research. We also acknowledge Idaho Department of Fish and Game, USDA APHIS Wildlife Services, USDA Forest Service, and Nez Perce Tribe for their support and cooperation. 